\title{
Reseña
}

\section{Que otros sean lo normal - tensiones entre el movimiento LGTB y el activismo queer}

\section{Mayte Cantero Sánchez}

Universidad Autónoma de Barcelona

cantero.mayte@gmail.com

Leandro Colling

Editorial EGALES.

Barcelona, 2019.

Pp.243

Idiomas: español

ISBN: 9788417319502

Fecha de recepción: 30 de octubre de 2019.

Fecha de aprobación: 11 de diciembre de 2019.

La manera en la que diferentes actores sociales escogen las estrategias políticas en torno a un eje de opresión son múltiples y a menudo contradictorias. El libro Que otros sean lo normal tensiones entre el movimiento LGTB y el activismo queer de Leandro Colling, de reciente aparición (2019) en España, ahonda en las similitudes y diferencias de las agendas en torno a los derechos LGBTI por parte de movimientos institucionalizados y colectivos de disidencia sexo-genérica. Es una obra que presenta realidades políticas con sus múltiples aristas mediante un estilo fluido y accesible sin por ello simplificar su argumentario.

Leandro Colling es profesor e investigador en la Universidad Federal de Bahía en Salvador, además de un exponente de los estudios queer en Brasil. Para la redacción de la presente obra -llevada a cabo en el marco de su etapa postdoctoral en Portugal- el autor examinó las tensiones y los diálogos entre el movimiento LGBTI y el activismo queer y/o de 
disidencia sexual y de género en las capitales de España, Portugal, Argentina y Chile. Con este objetivo, el autor visitó estos países entre 2013 y 2014 y realizó 35 entrevistas extensas con activistas y actores claves de los movimientos locales o estatales. La metodología cualitativa empleada es mixta puesto que combina la exposición de datos históricos de cada contexto con el análisis de la producción bibliográfica local y entrevistas en profundidad.

Esta metodología mixta viene justificada por un posicionamiento político y epistemológico que rompe con la diferencia entre sujeto que estudia y el objeto estudiado, fuertemente influenciado por las propuestas feministas y decoloniales que dan cuenta de la política de enunciación y que denuncian mediante este gesto la falsa objetividad de la que presume el conocimiento académico y científico. La metodología empleada es coherente con la manera en la que se estructura el texto, el cual rechaza la división clásica entre presentación de marco teórico y ulterior aplicación del mismo sobre el objeto a analizar.

Este cuestionamiento metodológico y formal y estas elecciones políticas y epistemológicas rompen el esquema narrativo clásico de los ensayos académicos: la forma en la que se detallan las vicisitudes, los desencuentros e imprevistos recogen la deriva y las complicaciones propias de los estudios de índole cualitativa, en los que el resultado final nunca está asegurado de antemano. Por tanto, más que un libro académico o un objeto cultural cerrado, la lectura de Que otros sean lo normal es la exposición de un proceso y una invitación sugerente a formar parte de esta deriva, de este vaivén contingente de encuentros, urbes y geografías nocturnas: El libro está estructurado en estos tres capítulos: "Ligando en...." realiza un primera aproximación histórica del contexto de los cuatro países, "Follando en..." da cuenta de las entrevistas en profundidad en dichos contextos y, por último, "Fumándose un cigarrillo en..." sirve para recoger reflexiones a modo de cierre provisional. A lo largo de estas páginas el autor nos invita a conocer los entresijos de la constitución de la escena queer/trans en Lisboa, los debates en torno al trabajo sexual y la cuestión migrante en Madrid, la potencia política de las personas trans* en Argentina al lograr una ley de identidad de género (2012) con una visión despatologizante o la crítica geopolítica a lo queer/cuir desde Chile con figuras como Pedro Lemebel o Hija de Perra.

El libro de Leandro Colling traza una cartografía escurridiza e inconclusa que otorga contexto histórico en torno a los movimientos LGBTI/queer en los cuatro países analizados, así como la situación legislativa del colectivo y sus demandas jurídicas. En todos los contextos tratados está presente la tensión entre, por una parte, los movimientos autónomos 
con su deseo de devenir minoritario opacos a las técnicas de gubernamentabilidad y, por otra parte, las instituciones que pretenden salvar los escollos que impiden a la población LGBTI disfrutar de los privilegios y los derechos que detenta la ciudadanía heteronormada. En la base de estas diferenciaciones residen conceptualizaciones totalmente diversas de qué significación se le da a la transformación social o qué postura se toma en torno a otros ejes de opresión (necesariamente imbricados y presentes en la producción de la disidencia sexual) como el racismo, el capitalismo o el capacitismo. Por ejemplo, múltiples movimientos LGBTI institucionalizados tienen posturas universalistas (y por extensión colonialistas) y se pliegan perfectamente a las lógicas neoliberales de diversificación de mercado.

A lo largo del texto Leandro Colling sostiene una lógica de la complementariedad y simultaneidad entre las luchas institucionales y las disidentes, rechazando una idea pura y prístina del sistema en contraposición a la subversión de lo queer:

[...] la necesidad de hacer política a escala macro, de adaptarse a los conceptos limitados de cómo son producidas estas políticas, como dice Berkins, es con frecuencia otro argumento esgrimido por muchas personas del activismo para criticar los estudios queer. En mi opinión se trata de otra crítica equivocada, ya que no conozco ningún trabajo vinculado a los estudios queer que haya defendido que las políticas públicas realizadas a escala macro, sean innecesarias, o que podríamos abdicar completamente de la afirmación identitaria. [...] lo que los estudios y activismos queer hacen es pensar sobre los límites de estas políticas a escala macro, qué otras políticas deben de realizarse y cómo podemos lidiar con las que ya tenemos (p.172).

Zafándose de las críticas que se realizan a lo queer como un estudio sobre lo "meramente cultural" - entendiendo aquí lo cultural como algo suplementario, superficial y separable-, Colling propone una visión afirmativa y productiva de la perspectiva queer. Por tanto, este prisma no sería pura negación de lo establecido sino un espacio para una crítica cultural que permitiría ensanchar el horizonte de las políticas públicas. Operativizar la mirada y legislar con perspectivas como la queer, que surgen precisamente al constatar las consecuencias nefastas de la categorización sexo-genérica por parte de los Estados es, sin duda, un desafío conceptual. Sin embargo, no por ello se puede prescindir de esta mirada desestabilizadora y desafiante a las categorías, incluso a aquellas empleadas por colectivos vulnerabilizados.

En resumen, Que otros sean lo normal de Leandro Colling traza un mapa afectivo ameno e incisivo; a través de una prosa entre la teoría y la crónica propone una imagen inconclusa de las tensiones entre la institucionalización y el "afuera" en Argentina, Chile, España y Portugal, permitiendo establecer un diálogo transnacional sobre las nociones claves 
y las estrategias necesarias para lograr emanciparnos de la cisheteronorma. Ahora bien, en disputa está cuál es el objetivo último de esta emancipación: habrá quien desee ser normal, y habrá quien, en palabras de Susy Shock recogidas por Leandro Colling, habrá quien prefiera que otros sean lo normal. 